\title{
THE RESULTS OF THE CORRELATION ANALYSIS \\ OF DATA ON THE SELECTION OF FORCED \\ MOVEMENTS FROM THE ATO AREA
}

\section{Anna Huliaieva ${ }^{1}$ \\ Mykola Papucha ${ }^{2}$}

DOI: https://doi.org/10.30525/978-9934-588-15-0-121

Abstract. The subject of the research is the system of beliefs of the person in crisis conditions. The purpose is to cover the results of correlation analysis on the sample of internally displaced persons from the ATO area. Concepts such as "migration" and "forced migration" are considered. These include "refugees" and "internally displaced persons". An analysis of such concepts as "beliefs" and "belief systems" is presented. Emphasis is placed on the importance of basic beliefs that provide a person with a sense of security and stability. The psychological component of the formation of beliefs and their subsequent impact on human life are highlighted. Also, the possibility of influence of beliefs on crisis management is considered. The whole system of convictions of internally displaced persons from the ATO area (or at least part of it, which we were diagnosed using the Basic Belief Scale method) has a close relationship with satisfaction with their economic situation. This is one of the proofs of our hypothesis that the belief system is closely linked to how satisfied a person will be in life under new conditions - after being forced to move out of the ATO area. Also, this system of interconnections means that the more a person is satisfied with their economic situation, the more likely it is to have a positive image. I am confident in the goodwill of the world around, have positive perceptions of control, justice and luck. It should be noted that the correlation analysis shows that there is no component of the IDP's self-image, surrounding world, justice, control, and luck, which would not have at least several components of these people's satisfaction in different aspects of life.

\footnotetext{
${ }^{1}$ Graduate Student of the Department of General and Practical Psychology,

Nizhyn Mykola Gogol State University, Ukraine

${ }^{2}$ Doctor of Psychological Sciences, Professor,

Head of the Department of General and Practical Psychology,

Nizhyn Mykola Gogol State University, Ukraine
} 
On the other hand, 12 of the 14 components of life satisfaction (quality of life) have correlated relationships with the various components of the system of basic representations of IDPs from the ATO area. Only satisfaction with their leisure activities and satisfaction with their sex lives had no significant correlation with any component of the IDPs' basic beliefs. At the same time, this does not indicate that such relationships do not exist, they are simply not statistically proven and confirmed. According to the correlation analysis, people with a positive belief system about the value and significance of their own self, with the thought of being able to control events in their lives, expressed internality and consciousness of life are more satisfied with different aspects of their lives after the fact of forced relocation, and adapt accordingly. and have greater potential for self-realization. It is determined that, under conditionally identical circumstances, some forced migrants, despite the difficulties, build new lives, sometimes even more successful or more harmonious than they were before the war.

\section{Introduction}

Changes that occurred at the turn of the XX-XXI centuries, changes in the domestic and foreign policy of Ukraine determined the high relevance of the problem of migration. Unlike a voluntary change of residence (in search of, for example, improving living conditions), people are forced to move, usually as a result of military activities, harassment of the authorities, discrimination on the grounds of nationality, or religious beliefs.

According to the UN data, in connection with the 2014 events in Ukraine, the number of involuntary refugees and displaced persons from the Crimea, Luhansk and Donetsk regions is currently 1 million 230 thousand people. The media mentions even a larger number of 2.5 million people which has been the record point over the last decade across Europe. However, despite the fact that the Crimean and Donbas IDPs (involuntary displaced people) are internally displaced persons, which should significantly contribute to their social adaptation and further life, they are in reality refugees in their own country.

This directly brings enormous pressure on people who are forced to flee from their homes in connection with the relatively peaceful (Crimea) or frankly hostile actions (Donbass), experiencing stress, loss, distrust of their own country and against the background of social, legal and economic inequality that is demoralizing. 
Taking a decision to leave a historical homeland, people turn out to be in emergency, when fully formed life structures are destroyed, and there are virtually no clear and precise landmarks that determine the further sequence of events.

Analysis of recent research and publications. The term "beliefs" is increasingly found in the psychological literature in connection with the rapid development of cognitive and cognitive-behavioral areas of psychotherapy. A. Beck, A. Freeman, R. Bartlett, J. Piaget, S. Epstein, R. Yanoff-Bullman, R. Diltts studied beliefs. Scientists such as V. Kiger, J. Berry, M. Yuzhanin, N. Stukalenko, N. Ruchkova, N. Lebedev, G. Soldatova, F. Berezin, V. Gritsenko and others have studied such social phenomenon as crisis life situations. The analysis of scientific works shows the growing scientific interest in the problem of studying different aspects of behavior aimed at overcoming difficult situations for the individual (L. Antsiferova, R. Akhmerov, V. Bodrov, O. Bityeka, F. Vasiliuk, N. Volyanyuk, T. Kryukov, Maximenko, T. Titarenko).

The purpose is to cover the results of correlation analysis on the sample of internally displaced persons from the ATO area.

\section{Outline of the main research material}

As a result of the armed conflict in the Luhansk and Donetsk regions, the residents of these regions were forced to make a decision to leave their historic homeland. The initial conflict between the lack of positive motivation to move and the physical impossibility of further staying in the historical homeland, traumatization of the psyche due to the reasons and history of migration, as well as the difficulties of adaptation to a new place, determine the formation of a very specific experience of the IDPs which is beyond usual and daily.

The phenomenon of forced migration is a complex and multifaceted process. The terms "migration" and "forced migration" include a number of terms. Firstly, the terms "refugees" and "internally displaced persons" refer to them.

In accordance with UNHCR guidelines on the movement of persons within the country, persons displaced within the country are defined as people or groups of people who were forced to flee or leave their homes or places of residence because of or in order to avoid the effects of armed conflict, situations of general violence, human rights violations or natural 
disasters, manmade disasters who have not crossed the country's internationally recognized national border [2, p. 31].

In the history of our country, there was no such population group before. During the current state of Ukraine, we did not know what armed conflict, armed hostilities, external aggression, and civil war were. Leaving their native places, people hoped to return home soon.

Forced resettlement is considered one of the most difficult situations in life. Traumatization of the psyche in the past is premised on the history of migration, traumatization of the psyche in the new socio-cultural environment is caused by the requirements of adaptation and other difficulties that appear after moving. It can rightly be regarded as extreme when facing the problem of survival, the constant struggle with difficult life circumstances.

The surveys show that more than half of the former residents of Donbass have not been able to get used to the new circumstances. The most pressing issues for them were and still are housing and employment. According to a poll conducted by the Institute for Regional Studies n.a. M.I. Dolyshnii NASU, forced displaced persons who moved to the Lviv region, named unsolved housing issues (87.2\% of respondents) and employment (65.7\%) as the leading economic problems. The similar situation is observed in other regions of the country. For example, $90 \%$ of internally displaced persons in the Kharkiv region, $88 \%$ in the Zaporizhzhya region, $86 \%$ in the Dnipropetrovsk and Mykolaiv regions report about housing problems. Besides, in Ukraine there is a clear dependence of the exercise of citizens' rights opportunities on their place of residence (registration). Residents, having been forced to leave their territorial communities, have lost some of their civil rights and freedoms enshrined in the Constitution. This situation has become an objective factor in their discrimination in the places of forced settlement, which further complicates the process of their adaptation to new living conditions.

\section{Understanding the term "belief"}

An important role in the decision-making process of a person about further actions for his survival and adaptation to changing conditions is the presence of basic already formed beliefs.

Beliefs are views, knowledge, ideas that have become the motives of human behavior and determine its attitude to different spheres of reality; 
components of personality outlook [1, p. 364]. The presence of beliefs has to do with the recognition and direct experience of their truth, and with the need to realize them. You can talk about moral, scientific, religious and other beliefs.

Basic beliefs provide a person with a sense of safety and stability, however, there are situations (extreme negative experience) that dramatically change basic beliefs: in one moment, a person faces the horror generated by the outside world, as well as with their own vulnerability and helplessness; previously existent a certainty of self-protection becomes an illusion, which collapse drives the individual into a state of disintegration. The overcoming trauma process is to restore basic beliefs, although, it does not occur completely, but to a certain level, which frees a person from the illusion of invulnerability of the country [4, p. 78].

Beliefs arise through experience. Experience requires prior beliefs and a reason to be integrated with new experience to form new beliefs in the system. In turn, sequences must form the experience, because existing beliefs need reason. It is the personal experience that gives rise to certain feelings and emotions in the person, attitude to the environment. The most important are the lifestyle and traditions of the family, the nature of relationships with the surrounding, that is, the consolidation of basic beliefs influenced by macro-, meso- and micro-factors. True beliefs begin to emerge in adolescence and older school age [6, p. 10]. It happens due to the acquisition of broader and deeper knowledge, the emergence of advanced forms of thinking, the formation of active life position and outlook.

\section{The belief system}

Beliefs are most often formed as a result of purposeful world cognition, but also as a result of uncritical assimilation of existent beliefs, in addition, they can arise under the influence of various mechanisms of psychological protection. As a result of the adoption at the level of the mind of any concepts, categories, statements, positions as truth - creates a system of beliefs of the person: generalization, ideas, decisions made about himself, his character, values, abilities, behavior; about people, relationships with them and the world around them. The belief system, in turn, shapes the paradigm of life, creates the basis of a worldview, which gives a person confidence in life, forms a backbone that integrates worldview, knowledge and assess- 
ment of reality [5]. Beliefs direct behavior and serve as the basis of willful actions to achieve life goals.

Beliefs help explain cause and effect. Cause and effect is a convenient explanation for when one event happens right after another without delay and deviation. The further, in relation to time, events occur, the more difficult it is to claim that one "caused" the other, because many other events manage to happen between them [3, p. 98].

The belief system is a set of personality inclinations for the consistent perception, explanation and interpretation of stimuli or events. Each person has certain central or basic concepts that guide him in his efforts to reconcile his personal world. Humans have conceptual systems that are ways of interpreting or measuring relevant aspects of their world. These systems are characterized by some form of structure or relationships between different parts of the system.

It is believed that the personality develops conceptually through stages, from undifferentiated and concrete to more integrated and abstract. The more specific end of the measurement is a state of minimal differentiation, and abstractness is a high differentiation and integration. People will vary depending on the degree of differentiation and relativism they achieve and aim at structuring their environment in accordance with their own conceptual belief system. Differences in differentiation and relativism determine the openness and closedness of the system, its susceptibility to deflecting elements and the ability to tolerate external shocks. Greater abstractness can be seen as great openness and great tolerance for the different and the new [2, p. 49].

A person's belief system influences his perception, knowledge and actions, as well as influences his psychological processes and behavior. The actions of individuals involved in the decision-making process are influenced by their belief systems and concepts. Thus, the individuals of each system must display variations in their perceptions, beliefs, and actions.

For the correlation analysis, we have chosen the Spearman coefficient because it is nonparametric and is suitable for the samples that do not meet the normal distribution. For our sample of IDPs from the ATO area $(n=114)$ this is relevant because the normal distribution of data has not been diagnosed. In the course of the correlation analysis, two psycho-diagnostic methods were examined: 1) "Quality of Life Satisfaction Questionnaire" 
by Jean Endicott); 2) "World Assumptions Scale (WAS)", developed by R. Yanov-Bulman, adapted and restarted by M.A. Padun, A.V. Kotelnikova. Significant correlation relationships are listed in Table 1.

Table 1

\section{Correlations between the scores on the sample of IDPs by the Spearman coefficient $(n=114)$}

\begin{tabular}{|l|c|c|c|c|c|}
\hline & $\begin{array}{c}\text { Self } \\
\text { Image } \\
\text { Subscale }\end{array}$ & $\begin{array}{c}\text { Goodwill } \\
\text { of the } \\
\text { World } \\
\text { Subscale }\end{array}$ & $\begin{array}{c}\text { Justice } \\
\text { Subscale }\end{array}$ & $\begin{array}{c}\text { Luck } \\
\text { Subscale }\end{array}$ & $\begin{array}{c}\text { Control } \\
\text { Belief } \\
\text { Subscale }\end{array}$ \\
\hline $\begin{array}{l}\text { 1. Satisfaction with } \\
\text { physical health }\end{array}$ & $0,283^{* *}$ & $0,188^{*}$ & & $0,301^{* *}$ & $0,284^{* *}$ \\
\hline 2. Satisfaction with mood & $0,299^{* *}$ & & $0,304^{* *}$ & $0,348^{* *}$ & $0,210^{*}$ \\
\hline 3. Satisfaction with work & $0,267^{* *}$ & & $0,305^{* *}$ & $0,254^{* *}$ & \\
\hline $\begin{array}{l}\text { 4. Satisfaction with } \\
\text { housework (activity) }\end{array}$ & $0,253^{* *}$ & $0,287^{* *}$ & $0,317^{* *}$ & $0,297^{* *}$ & $0,219^{*}$ \\
\hline $\begin{array}{l}\text { 5. Satisfaction with } \\
\text { relation with people }\end{array}$ & $0,363^{* *}$ & $0,398^{* *}$ & $0,273^{* *}$ & $0,286^{* *}$ & $0,197^{*}$ \\
\hline $\begin{array}{l}\text { 6. Satisfaction with } \\
\text { family relations }\end{array}$ & & & & $0,202^{*}$ & \\
\hline $\begin{array}{l}\text { 7. Satisfaction with } \\
\text { leisure, activities in your } \\
\text { free time }\end{array}$ & & & & & \\
\hline $\begin{array}{l}\text { 8. Satisfaction with ability } \\
\text { to cope with daily routine }\end{array}$ & $0,186^{*}$ & & $0,271^{* *}$ & & $0,399^{* *}$ \\
\hline 9. Satisfaction with sex life & & & & & $0,510^{* *}$ \\
\hline $\begin{array}{l}\text { 10. Satisfaction with your } \\
\text { economic situation }\end{array}$ & $0,310^{* *}$ & $0,374^{* *}$ & $0,259^{* *}$ & $0,429^{* *}$ & $0,297^{* *}$ \\
\hline $\begin{array}{l}\text { 11. Satisfaction with } \\
\text { living conditions }\end{array}$ & & $0,225^{*}$ & $0,334^{* *}$ & $0,316^{* *}$ & $0,241^{* *}$ \\
\hline $\begin{array}{l}\text { 12. Satisfaction with } \\
\text { ability to rise without } \\
\text { dizziness, rocking or } \\
\text { falling }\end{array}$ & $0,220^{*}$ & $0,190^{*}$ & $0,349^{* *}$ & $0,286^{* *}$ & $0,290^{* *}$ \\
\hline $\begin{array}{l}\text { 13. Satisfaction with your } \\
\text { attitude to hobby and work }\end{array}$ & $0,200^{*}$ & $0,202^{*}$ & $0,290^{* *}$ & $0,228^{*}$ & $0,260^{* *}$ \\
\hline $\begin{array}{l}\text { 14. Satisfaction with } \\
\text { general sense of well- } \\
\text { being }\end{array}$ & $0,447^{* *}$ & $0,404^{* *}$ & $0,346^{* *}$ & 0,5 & \\
\hline
\end{tabular}


On the whole, the relationships found indicate that there are multilevel and multifaceted correlations between the beliefs of migrants and their satisfaction with different dimensions of their lives. This testifies to our general hypothesis of the fundamental synergies between the beliefs of displaced persons from the ATO area and their satisfaction with life. Especially relevant at the present stage is the study of life satisfaction and peculiarities of the belief system of the individual in crisis conditions (of the IDPs from the ATO zone). In regard to mentioned, T.M. Titarenko notes: "In Ukraine, general sociogenic stress is aggravated by the prolonged and massive traumatization of the population associated with the unannounced war. The peculiar, hybrid nature of this war makes it difficult to perceive what is happening, leading to a deterioration of health, and a decrease in the level of psychological well-being" [5, p. 5]. Taking into account these peculiarities, a correlation analysis of the connection between satisfaction with different aspects of life (quality of life) and the system of basic representations of personality was made in a sample of internally displaced persons from the anti-terrorist operation $(\mathrm{n}=114)$.

In the course of correlation analysis, such relationships have been identified and interpreted. Satisfaction with Physical Health (according to the "Quality of Life Satisfaction Questionnaire - Q-LES-Q-SF, Jean Endicott") correlates with Self Image Subscale 1 (according to the method "World Assumptions Scale (WAS)" developed by R. Yanov-Bulman, adapted and restarted by MA Padun, AV Kotelnikova), $r=0,283, p<0,01$; with Goodwill of the World Subscale 2 (using the "Basic Belief Scale" method), $\mathrm{r}=0.188, \mathrm{p}<0.05$; with Luck Subscale 4 (according to the "Basic Belief Scale" method), $r=0,301, \mathrm{p}<0,01$; Control Belief Subscale 5 (using the "Basic Belief Scale" method), $r=0.284, \mathrm{p}<0.01$.

Satisfaction with one's physical health is one of the fundamental foundations that make it possible to build other parameters of life satisfaction and general understanding of the world. The IDPs, satisfied with their physical health, tend to have a more positive self image, tend to perceive the surrounding world as more supportive, tend to interpret themselves as those whom luck more often smiles at. Finally, the connection between control beliefs and satisfaction with one's physical health has been identified. But since it is a correlation, that is, we cannot find out what the cause is, we should hypothesize that the reverse tendency may occur - people's tendency 
to take a more positive view of themselves, the world around them, their luck and their level of life control can be deeply linked to a better level of physical health. Modern psychological research shows that often the most important thing is how we perceive the world around us, how we interpret it, and what beliefs underlie it. The close relationship we have found between the satisfaction with physical health and the four of the five subscales of the Basic Belief Scale methodology allows us to deeply analyze the phenomenology of the interdependence of these variables. The fact that the data obtained are characteristic of the sample of internally displaced persons from the ATO zone is probably not accidental. The tendency of lower satisfaction of internally displaced persons in all 14 spheres of life, diagnosed with the method of "Scale of Satisfaction with Life (Quality of Life)" by J. Endicott, revealed by us at the primary level of mathematical processing shows that different parameters of life satisfaction are especially important for this sample, and, consequently, the connection of satisfaction with different life parameters with basic beliefs. This not only confirms the high relevance of our research, but also qualitatively characterizes our sample of internally displaced persons from the ATO area. Let us turn to the analysis of other correlative relationships which will enable us to understand more deeply the specifics of the psychological characteristics of life satisfaction and beliefs of internally displaced persons.

Satisfaction with one's mood (according to the method "Scale of Satisfaction with Life (Quality of Life)" by J. Endicott) correlates with Self Image Subscale 1 (according to the method "Basic Belief Scale"), $r=0,299$, $\mathrm{p}<0,01$; with Justice Subscale 3 (by the "Basic Belief Scale" method), $\mathrm{r}=0.304, \mathrm{p}<0.01$; with Luck Subscale 4 (according to the "Basic Belief Scale" method), $r=0,348, \mathrm{p}<0,01$; Control Belief Subscale 5 (using the "Basic Belief Scale" method), $\mathrm{r}=0.210, \mathrm{p}<0.05$.

The correlation was found between satisfaction with one's mood and four of the five subscales of the Basic Belief Scale. The more a displaced person is satisfied with his mood, the more positive self image will have, the more he will perceive the surrounding world as fair, and the more important for him luck and control belief will be. On the whole, the large number of correlative relationships between different life satisfaction parameters and the personality belief system indicates that a sample of forced IDPs is characterized by a fundamental relationship between life satisfaction and 
how life is perceived and interpreted. The fact that only correlative connections with the "+" sign were found suggests that the general trend is the following: he greater a person's satisfaction with a certain parameter of quality of life, the more he is inclined to positively perceive himself and the world around him. Conversely: the more positively one interprets the self image, the potential benevolence of the outside world, justice, luck, and control, the more one will be satisfied with one's life in its various characteristics. However, this tendency has its specific characteristics for different specific relationships. For example, satisfaction with one's mood does not have a significant correlation with Goodwill of the World Subscale 2. This does not indicate that there is no relationship between these variables, but at the same time forces psychological analysis to address primarily those variables, between which a significant correlation was found at least at the significance level $\mathrm{p} \leq 0.05$.

Satisfaction with one's work (according to the method "Scale of Satisfaction with Life (Quality of Life)" by J. Endicott) correlates with Self Image Subscale 1 (according to the method "Basic Belief Scale"), $r=0,267$, $\mathrm{p}<0,01$; with Justice Subscale 3 (by the "Basic Belief Scale" method), $\mathrm{r}=0.305, \mathrm{p}<0.01$; with Luck Subscale 4 (according to the "Basic Belief Scale" method), $r=0.254, \mathrm{p}<0.01$.

The more positive a person's self image is, the more favorable his beliefs about justice and luck in his life are, the more he will be satisfied with his work. For the displaced persons, the factor of satisfaction with their work should be quite significant, as most of them were forced to change their jobs. Here again, it will be appropriate to consider that it will depend on the person himself, how he will perceive the situation and, accordingly, how satisfied he will be with various aspects of life. A person's deep conviction that he or she is a good professional, that the world is fair, and luck can often be present in his or her life, will lead to greater satisfaction with the person's work. According to O. Noskova, the motivation of work can be considered in two aspects: in connection with production efficiency and in connection with human development as a subject of labor [6]. Satisfaction of internally displaced persons from the ATO area with their work can also be considered in these two aspects: 1) satisfaction as a factor of higher labor efficiency; 2) satisfaction as a factor of further personality professionalism. 
Satisfaction with one's housework (activity) (by J. Endicott's "Scale of Satisfaction with Life (Quality of Life)") correlates with Self Image Subscale 1 (by the "Basic Belief Scale"), $r=0.253, p<0,01$; with Goodwill of the World Subscale 2 (using the "Basic Belief Scale" method), $r=0.287$, $\mathrm{p}<0.01$; with Justice Subscale 3 (by the "Basic Belief Scale" method), $\mathrm{r}=0.317, \mathrm{p}<0.01$; with Luck Subscale 4 (according to the "Basic Belief Scale" method), $r=0.297, \mathrm{p}<0.01$; Control Belief Subscale 5 (using the "Basic Belief Scale" method), $r=0.219, \mathrm{p}<0.05$.

Correlation between all subscales of the Basic Belief Scale methodology was found with such indicator of the quality of life of internally displaced persons as satisfaction with their housework (activity). Thus, the system of beliefs of internally displaced persons is significantly correlated with satisfaction with their domestic activity. What is interesting is that all the beliefs of the IDPs - about their self image, the benevolence of the outside world, justice, luck and control - have to do with home activity. As all these people have recently changed their place of residence, they have different homes than before, and their home activity has changed qualitatively. At the same time, how satisfied people are with their housework in these new circumstances is closely linked to their belief system. This confirms our basic assumption that a person's belief system causes life satisfaction in different areas. And it has been empirically established that such an indicator of life satisfaction as satisfaction with home activity is one of the most sensitive to the belief system of the individual, his or her self-beliefs, world, luck, control and justice.

Satisfaction with one's relationships with people (according to J. Endicott's Scale of Satisfaction with Life (Quality of Life)) correlates with Self Image Subscale 1 (according to the "Basic Belief Scale" method), $r=0.363$, $\mathrm{p}<0.01$; with Goodwill of the World Subscale 2 (using the "Basic Belief Scale" method), $\mathrm{r}=0.398, \mathrm{p}<0.01$; with Justice Subscale 3 (by the "Basic Belief Scale" method), $r=0.273, \mathrm{p}<0.01$; with subscale Luck Subscale 4 (according to the "Basic Belief Scale" method), $\mathrm{r}=0,286, \mathrm{p}<0.01$; Control Belief Subscale 5, (using the "Basic Belief Scale" method), $r=0.197, \mathrm{p}<0.01$.

Interestingly, satisfaction with one's relationships with people correlates with all the components of our belief system we diagnose, while satisfaction with one's family relationships only correlates with beliefs about luck. In native psychology, the relations of a person with other people are 
researched in various ways. In particular, we should mention the schools of V. Myasishchev (psychology of relations) and O.Bodalyov (psychology of communication). The empirically established fact that satisfaction with relationships with others has significant correlations both with the self image, and with the belief in the goodwill of the world around, and with the luck, control and justice beliefs, demonstrates the benefit that the global belief system of internally displaced people is significantly interconnected with relations with others. Indeed, if a person interprets himself positively, the world as safe and benevolent, if he has a constructive idea of justice, luck and control, then that person will be more likely to engage with other people, who will satisfy all parties. Conversely, people with negative, destructive, disadvantaged beliefs about the world will be inclined to build less satisfactory relationships with others. But this does not apply to family relationships that we will now attempt to analyze.

Satisfaction with one's family relationships (by J. Endicott's Scale of Satisfaction with Life (Quality of Life)) correlates with Luck Subscale 4 (using the Scale of Basic Beliefs), $r=0.202, p<0.05$.

The fact that satisfaction with family relationships correlates with beliefs about luck and not with other components of the IDP's belief system indicates that a person will be somewhat satisfied with relationships with his family, no matter how safe and favorable the world around him may seem, how positively he will perceive himself and how constructive his beliefs in control and fairness will be. A certain level of satisfaction with family relations will be maintained in the conditions of quite different beliefs of a person about himself, the world around him, control and justice. The only thing that has to do with the satisfaction of family relationships of internally displaced persons from the ATO area is the belief in luck. In other words, the more fortunate a person will feel, because of the circumstances of his life, because right these people are his family, the more satisfied he will be with his relatives. To a certain extent, relationships with the family are not dependent on the system of person's beliefs in crisis, except luck beliefs.

Satisfaction with one's ability to cope with daily responsibilities (according to J. Endicott's Scale of Satisfaction with Life (Quality of Life)) correlates with Self Image Subscale 1 (according to the "Basic Belief Scale"), $\mathrm{r}=0,186, \mathrm{p}<0.05$; with Justice Subscale 3 (using the "Basic Belief Scale" method), $r=0.271, p<0.01$. The fact that satisfaction with one's ability to 
cope with day-to-day responsibilities is closely linked to self-beliefs and beliefs about justice is deeply natural and psychologically reasonable. This means that the more positively and constructively a person perceives himself and, at the same time, the fairer he considers, in particular, the distribution of daily responsibilities and the need to fulfill them, the more the individual will be satisfied with his ability to be effective in daily tasks. American psychologist M. Cixentmigai, developing his theory of flowing experiences, argues that even pursuing the most mundane daily chores can be fun and enjoyable if you focus on the task at hand and consciously enhance your level of skill.

Satisfaction with one's economic situation (according to the methodology of the J. Endicott Scale of Satisfaction with Life (Quality of Life)) correlates with Self Image Subscale 1 (according to the "Basic Belief Scale" method), $r=0.310, p<0.01$; with Goodwill of the World Subscale 2 (using the "Basic Belief Scale" method), $r=0.374, \mathrm{p}<0.01$; with Justice Subscale 3 (by the "Basic Belief Scale" method), $r=0.259, \mathrm{p}<0.01$; with Luck Subscale 4 (according to the "Basic Belief Scale" method), $\mathrm{r}=0,429, \mathrm{p}<0.01$; Control Belief Subscale 5 (using the "Basic Beliefs" method), $\mathrm{r}=0.297, \mathrm{p}<0.05$.

The whole belief system of internally displaced persons from the ATO area (or at least part of it, which diagnosed using the Basic Belief Scale method) has a close relationship with satisfaction with their economic situation. This is one of the corroboration of our hypothesis that the belief system is closely linked to how satisfied a person will be in life under new conditions - after being forced to move out of the ATO area. Also, this system of interconnections means that the more a person is satisfied with his economic situation, the more likely he is to have a positive self image, confident in the goodwill of the world around, has positive perceptions of control, justice and luck.

Satisfaction with their living conditions (by J. Endicott's Scale of Satisfaction with Life (Quality of Life)) correlates with Goodwill of the World Subscale 2(by "Basic Belief Scale" method), $r=0.225, \mathrm{p}<0.05$; with Justice Subscale (according to the "Basic Belief Scale" method), $r=0,334$, $\mathrm{p}<0,01$; with Luck Subscale 4 (according to the "Basic Belief scale" method), $\mathrm{r}=0,316, \mathrm{p}<0.01$; Control Belief Subscale 5 (using the "Basic Belief Scale" method), $\mathrm{r}=0.241, \mathrm{p}<0.05$. 
The extent to which a person is satisfied with their living conditions correlates with four of the five parameters of the system of convictions of internally displaced persons from the ATO area. Housing conditions are one of the factors in the life of internally displaced persons that has changed the most since moving out of the ATO area. Interestingly, satisfaction with living conditions does not correlate with self image. Satisfaction with their living conditions will be higher, the more constructive ideas of the person about the world as a benevolent and safe place, the more the person is convinced of the fairness and controllability of events, and also the more he considers himself susceptible to luck.

Satisfaction with one's ability to rise without dizziness, rocking, or falling (according to J. Endicott's Scale of Satisfaction with Life (Quality of Life)) correlates with Self Image Subscale 1 (according to the "Basic Belief Scale" method), $r=0.220, p<0.05$; with Goodwill of the World Subscale 2 (according to the "Basic Belief Scale" method), $r=0,190, p<0,05$; with Justice Subscale (according to the "Basic Belief Scale" method), $\mathrm{r}=0,349, \mathrm{p}<0,01$; with Luck Subscale 4 (according to the "Basic Belief Scale" method), $r=0,286, p<0.01$; Control Belief Subscale 5 (by the "Basic Belief Scale" method), $r=0.290, \mathrm{p}<0.05$.

Satisfaction with one's ability to rise without dizziness, rocking or falling is one of the basic pleasures, one that actually enables all other aspects of a person's life satisfaction and, in general, high human functionality. The fact that this satisfaction indicator has significant correlation with all indicators of the belief system: beliefs about self image and the goodwill of the world around, beliefs about control, justice and luck, is another confirmation of our hypothesis about the close relationship of life satisfaction with basic personality beliefs.

Satisfaction with your attitude to hobby and work (according to J. Endicott's Scale of Satisfaction with Life (Quality of Life)) correlates with Self Image Subscale 1 (according to the "Basic Belief Scale" method), $\mathrm{r}=0,200, \mathrm{p}<0,05$; with Goodwill of the World Subscale 2 (by the "Basic Belief Scale" method), $r=0.202, \mathrm{p}<0.05$; with Justice Subscale 3 (by the "Basic Belief Scale" method), $r=0.290, p<0.01$; with Luck Subscale 4 (according to the "Basic Belief Scale" method), $r=0.228$, $\mathrm{p}<0.05$; Control Belief Subscale 5 (using the "Basic Belief Scale" method), $\mathrm{r}=0.260, \mathrm{p}<0.01$. 
Satisfaction with your attitude to hobby and work is somewhat in tune with your already characterized job satisfaction, but a new component is added: satisfaction with your hobby attitude. It should be noted that in this type of satisfaction, not only job satisfaction and hobbies per se are essential, but first and foremost satisfaction with the attitude towards them. E.O. Klimov wrote: "In the psychological approach to work, all existing categories of psychological sciences are put into circulation, since the central issue here is the problem of human correspondence as a subject and in one way or another fixed in the culture (and in this sense objective) requirements for it as to "Producer" of something valuable. " Satisfaction with your attitude to work and hobbies is an important characteristic of a person as a subject of work and life. Correlation analysis has shown that this component of quality of life - satisfaction with one's attitude to work and hobbies - is closely interconnected with the whole system of basic beliefs of the individual, in particular the self image, justice, control, luck and goodwill of the surrounding world beliefs.

Satisfaction with general sense of well-being (according to J. Endicott's Scale of Satisfaction with Life (Quality of Life)) correlates with Self Image Subscale 1 (according to the "Basic Belief Scale" method), $r=0,447$, $\mathrm{p}<0.01$; with Goodwill of the World Subscale 2 (using the "Basic Belief Scale" method), $\mathrm{r}=0.404, \mathrm{p}<0.01$; with Justice Subscale 3 (by the "Basic Belief Scale" method), $\mathrm{r}=0.346, \mathrm{p}<0.01$; with Luck Subscale 4 (according to the "Basic Belief Scale" method), $r=0,510, p<0.01$; Control Belief Subscale 5 (using the "Basic Belief Scale" method), $r=0.399, \mathrm{p}<0.01$.

To some extent, satisfy the overall sense of well-being is an integral scale. Correlation analysis has shown that this integral indicator is closely interrelated with all components of the basic notions of internally displaced persons from the ATO area. It should be noted that the correlations of the Satisfaction with General Well-Being indicator with all subscales of the "Basic belief scale" methodology are of the highest importance among the other correlated relationships found. This is in favor of the assumption we have made about the interconnection of the displaced person's belief system with overall satisfaction and well-being.

The problem of psychological well-being in modern science is addressed by representatives of positive psychology. In Ukrainian science, we should first mention T. Titarenko, who, analyzing different approaches to psycho- 
logical well-being, sums up: "So, people who believe that everything in life depends on their own efforts are psychologically more prosperous than those who have much money. Internally prosperous people are more autonomous, able to interact with the environment. They are aimed at personal growth and strain after establishing and maintaining positive relationships with others. They have clear life goals, both long-term, distant and temporary, relevant. The basis for their internal well-being is a stable and adequate self-esteem" [5]. These data are consistent with those of our empirical study, in particular, those obtained using the correlation analysis method.

In summary, it should be noted that the correlation analysis shows that there is no component of the belief system of internally displaced persons about themselves, the world around them, justice, control and luck, which would have no connection with, at least, several components of these people's satisfaction with different aspects of life. On the other hand, 12 of the 14 components of life satisfaction (quality of life) have correlation with the various components of the basic belief system of IDPs from the ATO area. Only satisfaction with their leisure activities and satisfaction with their sex lives had no significant correlation with any component of the IDPs' basic beliefs. At the same time, this does not indicate that such connections do not exist, they are simply not statistically proven and confirmed.

\section{Conclusions}

In characterizing the generalized system of correlated relationships found, we should also point out that in the qualitative analysis of these relationships we used the logic of relating satisfaction with a particular aspect of life to the components of the belief system. It can be assumed that if a different logic were adopted and the components of the belief system of internally displaced persons were taken as the basis of the analysis, then somewhat more nuanced results could be obtained. However, the basic patterns would remain the same.

In general, the correlation analysis confirms the hypothesis of our study, according to which people with a positive belief system about the value and significance of their self image, with the thought of being able to control events in their lives, expressed internality and consciousness of life are more satisfied with different aspects of their lives after the fact of forced resettlement, and therefore better adapted and have greater potential for self-realization. 
The prospect of further research. In the near future, it is planned to develop and implement a training program aimed at psychological assistance to the individual in crisis situations, in particular in the conditions of forced resettlement.

\section{References:}

1. Dilts R. Izmenenie ubezhdeniy s pomoshch'yu NLP / Robert Dilts, per. s angl. V.P. Chursina. - M.: Nezavisimaya firma «Klass», 2000. - $192 \mathrm{~s}$.

2. Maslou A. Dal'nie predely chelovecheskoy psikhiki / Per. s angl. / Abrakham Maslou. - SPb.: «Evraziya», 1997. - $430 \mathrm{~s}$.

3. Nartova-Bochaver S.K. Chelovek suverennyy: psikhologicheskoe issledovanie subekta $\mathrm{v}$ ego bytii / Sofiya Kimovna Nartova-Bochaver. $-\mathrm{SPb}$.: Piter, 2008. $-400 \mathrm{~s}$.

4. Padun M. Psikhicheskaya travma i bazisnye kognitivnye skhemy / M. Padun, N. Tarabrina // Moskovskiy psikhoterapevticheskiy zhurn. - 2003. - № 1. S. $121-141$.

5. Titarenko T.M. Psikhologichne zdorov'ya osobistosti: zasobi samodopomogi $\mathrm{v}$ umovakh trivaloi travmatizatsii: monografiya / Tetyana Mikhaylivna Titarenko / Natsional'na akademiya pedagogichnikh nauk Ukraini, Institut sotsial'noi ta politichnoï psikhologii. - Kropivnits'kiy : Imeks-LTD, 2018. - $160 \mathrm{~s}$.

6. Dweck C.S. Mindset: The new psychology of success / C.S. Dweck. New York, NY, US: Random House, 2006. 